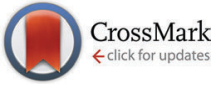

Cite this: Chem. Commun., 2016, 52, 1657

Received 18th November 2015, Accepted 2nd December 2015

DOI: $10.1039 / \mathrm{c5cc09566b}$

www.rsc.org/chemcomm

\section{Developing strongly luminescent platinum(Iv) complexes: facile synthesis of bis-cyclometalated neutral emitters $\uparrow$}

\author{
Fabio Juliá, ${ }^{a}$ Delia Bautista ${ }^{\mathrm{b}}$ and Pablo González-Herrero*a
}

\begin{abstract}
A straightforward, one-pot procedure has been developed for the synthesis of bis-cyclometalated chloro(methyl)platinum(Iv) complexes with a wide variety of heteroaromatic ligands of the 2-arylpyridine type. The new compounds exhibit phosphorescent emissions in the blue to orange colour range and represent the most efficient $\mathrm{Pt}(\mathrm{IV})$ emitters reported to date, with quantum yields up to 0.81 in fluid solutions at room temperature.
\end{abstract}

Luminescent transition-metal complexes have been exhaustively studied for their rich photochemistry and wide applicability in optical technologies. ${ }^{1}$ Thus, they are employed as electroluminescent materials, ${ }^{2}$ chemosensors, ${ }^{3}$ photocatalysts, ${ }^{4}$ probes for bioimaging, ${ }^{5}$ and photosensitizers for dye-sensitized solar cells ${ }^{6}$ and singlet-oxygen generation and photodynamic chemotherapy. ${ }^{7}$ The majority of studies concentrate on complexes of $\mathrm{d}^{6}$ [mainly $\mathrm{Ru}(\mathrm{II})$, Os(II) and $\operatorname{Ir}(\mathrm{III})], \mathrm{d}^{8}[\mathrm{Pt}(\mathrm{II}), \mathrm{Au}(\mathrm{III})]$ and $\mathrm{d}^{10}[\mathrm{Cu}(\mathrm{I})]$ ions with polypyridyls or cyclometalated arylpyridine ligands. ${ }^{1}$ The quest for stable complexes that exhibit highly efficient triplet emissions, relatively long excited-state lifetimes and tunable colours has been a constant in this field, associated with the need to improve the performance and reliability of specific applications; in this regard, research on cyclometalated Pt(II) ${ }^{8}$ and $\operatorname{Ir}(\mathrm{III})^{2 a, 9}$ complexes has been particularly intense, since these systems are highly versatile and can reach very high quantum yields.

In stark contrast with the numerous photophysical studies on complexes of other $\mathrm{d}^{6}$ ions, related works on Pt(Iv) complexes are scarce and appear to have been overshadowed by the strong focus on $\mathrm{Pt}(\mathrm{II}) .{ }^{8 f}$ Bis-cyclometalated complexes of the type $\left[\mathrm{Pt}\left(\mathrm{C}^{\wedge} \mathrm{N}\right)_{2}(\mathrm{R}) \mathrm{Cl}\right]\left[\mathrm{C}^{\wedge} \mathrm{N}=\right.$ ortho-deprotonated 2-phenylpyridine (ppy) or 2-thienylpyridine (thpy); $\left.\mathrm{R}=\mathrm{CH}_{2} \mathrm{Cl}, \mathrm{CHCl}_{2}\right]$ were the first luminescent $\mathrm{Pt}(\mathrm{Iv})$ complexes, with reported quantum yields in the range $0.05-0.15 .^{10}$ Later works have described weakly emissive Pt(Iv) complexes. ${ }^{11}$ Recently, we undertook the

\footnotetext{
${ }^{a}$ Departamento de Química Inorgánica, Facultad de Química, Universidad de Murcia, Apdo. 4021, 30071 Murcia, Spain.E-mail: pgh@um.es

${ }^{b}$ SAI, Universidad de Murcia, Apdo. 4021, 30071 Murcia, Spain

$\dagger$ Electronic supplementary information (ESI) available: Experimental details and characterization data. CCDC 1435571-1435574. For ESI and crystallographic data in CIF or other electronic format see DOI: 10.1039/c5cc09566b
}

development of highly efficient Pt(Iv) emitters and described a family of cationic homoleptic tris-cyclometalated complexes fac $-\left[\operatorname{Pt}\left(\mathrm{C}^{\wedge} \mathrm{N}\right)_{3}\right]^{+}$that exhibit high-energy (blue) emissions with quantum yields up to 0.49 and very long lifetimes. ${ }^{12}$ We then extended the study to heteroleptic derivatives $\operatorname{mer}\left[\mathrm{Pt}\left(\mathrm{C}^{\wedge} \mathrm{N}\right)_{2}\left(\mathrm{C}^{\prime \wedge} \mathrm{N}^{\prime}\right)\right]^{+}$ that display lower emission energies. ${ }^{13}$ These complexes emit from essentially ligand-centred triplet excited states $\left({ }^{3} \mathrm{LC}\right)$ with a very low but critical metal-to-ligand charge-transfer (MLCT) character, which facilitates the formation of the triplet emitting state because of the spin-orbit coupling effect induced by the metal. Here we present a series of phosphorescent bis-cyclometalated Pt(Iv) complexes of the type $\left[\mathrm{Pt}\left(\mathrm{C}^{\wedge} \mathrm{N}\right)_{2}(\mathrm{Me}) \mathrm{Cl}\right](\mathbf{2 a}-\mathbf{i}$; Scheme 1$)$, characterized by a
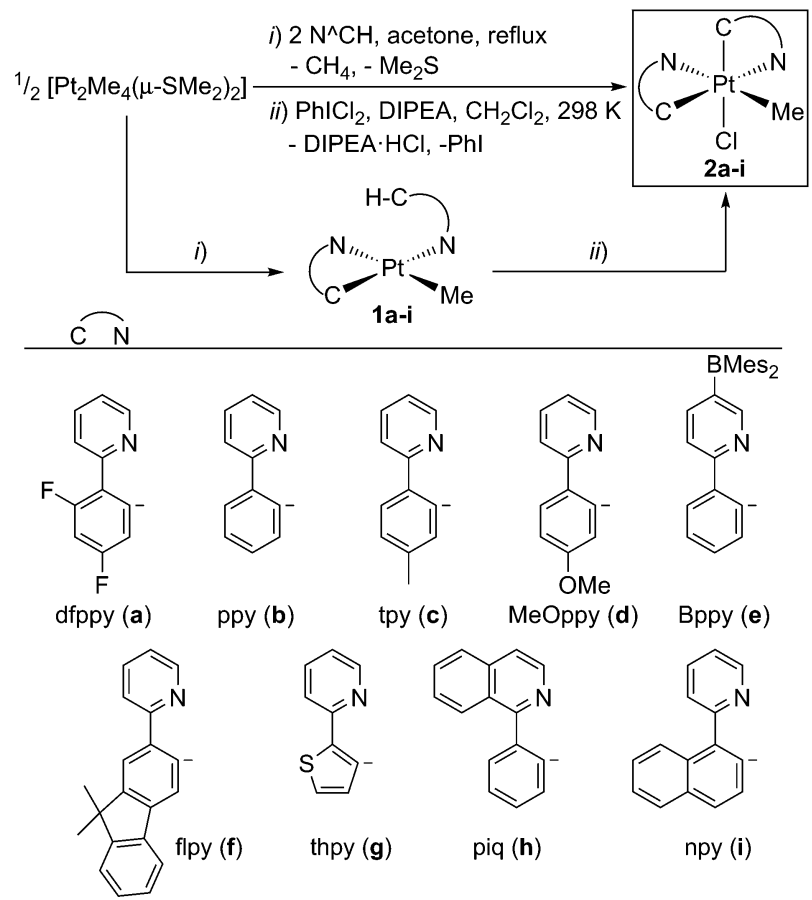

Scheme 1 One-pot synthesis of $\mathbf{2 a}$-i. DIPEA = N,N-diisopropylethylamine; Mes $=$ mesityl. 
high stability, tunable emission energies and generally high quantum yields, which make them very attractive as triplet emitters.

Compounds 2a-i were prepared following a one-pot, twostep procedure (Scheme 1). The first step is the reaction of $\left[\mathrm{Pt}_{2} \mathrm{Me}_{4}\left(\mu-\mathrm{SMe}_{2}\right)_{2}\right]^{14}$ with the $\mathrm{N}^{\wedge} \mathrm{CH}$ compound in 0.5:2 molar ratio in refluxing acetone, which leads to the cyclometalation of one $\mathrm{N}^{\wedge} \mathrm{CH}$ molecule and the coordination of a second one through the $\mathrm{N}$ atom to give the monocyclometalated $\mathrm{Pt}$ (II) complexes 1a-i. This result is consistent with the known reactivity of the binuclear precursor, which reacts with $\mathrm{N}^{\wedge} \mathrm{CH}$ compounds to give cyclometalated complexes of the type $\left[\operatorname{PtMe}\left(\mathrm{C}^{\wedge} \mathrm{N}\right)\left(\mathrm{SMe}_{2}\right)\right]$ and methane, while substitution of the labile $\mathrm{Me}_{2} \mathrm{~S}$ ligand allows further derivatization. ${ }^{15}$ Treatment of the intermediate derivatives $\mathbf{1 a}-\mathbf{i}$ with $\mathrm{PhICl}_{2}$ at room temperature resulted in the oxidation to $\mathrm{Pt}(\mathrm{IV})$ and subsequent metalation of the pendant aryl moiety of the coordinated $\mathrm{N}^{\wedge} \mathrm{CH}$ ligand to give complexes 2a-i. Similar metalations upon oxidation with $\mathrm{PhICl}_{2}$ have been reported for complexes of the type $\left[\mathrm{Pt}\left(\mathrm{C}^{\wedge} \mathrm{N}\right)\left(\mathrm{N}^{\wedge} \mathrm{CH}\right) \mathrm{Cl}\right]$ $\left(\mathrm{N}^{\wedge} \mathrm{CH}\right.$ trans to $\left.\mathrm{N}\right) .{ }^{16}$ The metalation reaction produces $\mathrm{HCl}$, which must be trapped by adding a base; otherwise, it rapidly reacts with complexes 1a-i, resulting in the substitution of the methyl ligand for a chloride (see the ESI $\dagger$ for details). The whole synthesis can be carried out without isolating the intermediate complexes 1a-i under atmospheric conditions and the final products can be obtained in moderate to excellent yields (57-89\%). It is worth emphasising that this method allows to prepare a wide range of derivatives from an easy-to-synthesize common precursor under mild conditions, typically consuming less than 6 hours.

The crystal structures of $\mathbf{2 a}, \mathbf{2 b}, \mathbf{2 d}$ and $\mathbf{2 f} \cdot \mathrm{CH}_{2} \mathrm{Cl}_{2}$ were solved by X-ray crystal diffraction studies. ${ }^{17}$ The molecular structure of $\mathbf{2 b}$ is depicted in Fig. 1 and the others are included in the ESI $\dagger$ along with selected bond distances and angles. The Pt-N bond distances are rather long (range 2.121-2.156 ̊) since the pyridyls are in trans to an aryl group or a methyl

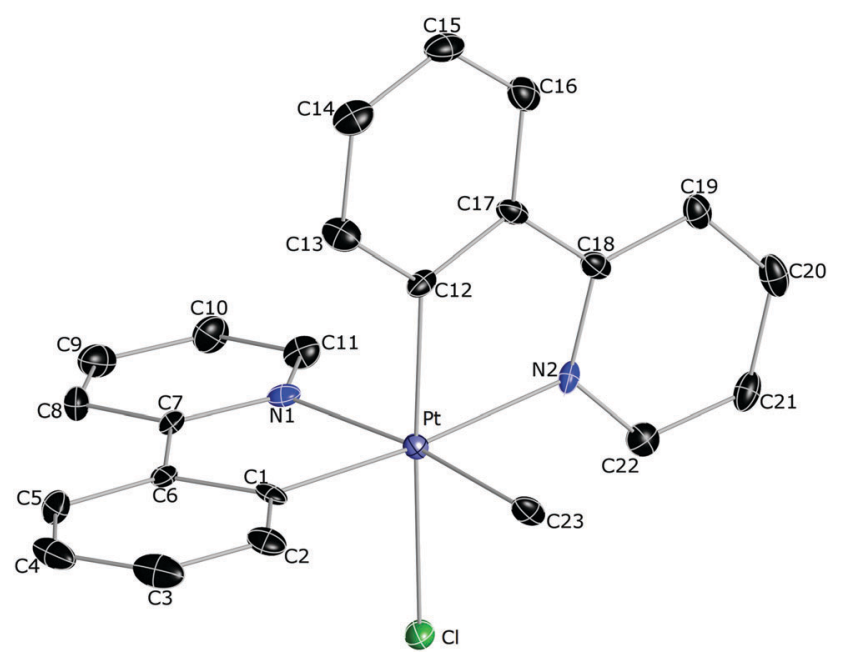

Fig. 1 Thermal ellipsoid representation (50\% probability) of the crystal structure of $\mathbf{2 b}$. Hydrogen atoms are omitted for clarity.
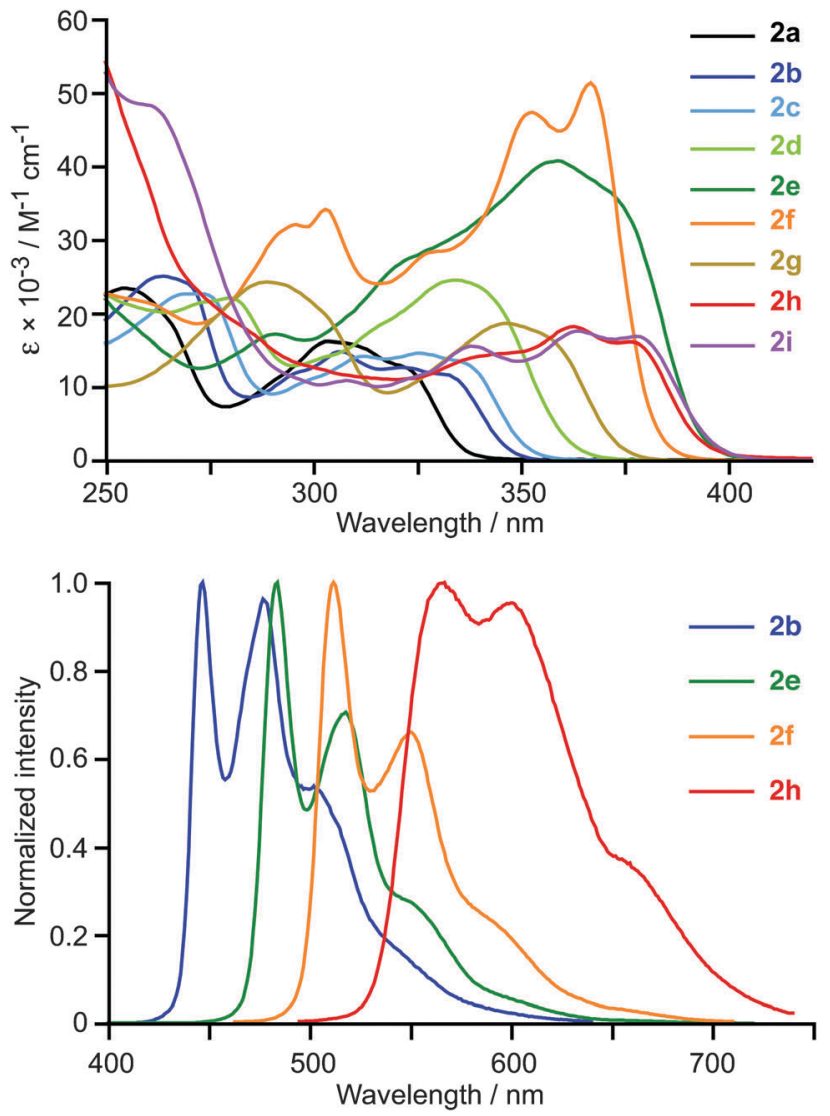

Fig. 2 Absorption spectra of compounds $\mathbf{2 a - i}$ (top) and selected emission spectra (bottom) in $\mathrm{CH}_{2} \mathrm{Cl}_{2}$ solution at $298 \mathrm{~K}$.

ligand, which exert very high trans influences. The Pt-Cl distances (2.423-2.446 $\AA$ ) are similar to those found in other $\mathrm{Pt}$ (Iv) complexes with a chloride ligand in trans to an aryl. ${ }^{16 b}$ Correspondingly, the Pt-C distances are very short (1.996-2.011 А), owing to the low trans influences of the pyridyl groups or the chloride ligand.

The absorption spectra of $2 \mathbf{a}-\mathbf{i}$ in $\mathrm{CH}_{2} \mathrm{Cl}_{2}$ solution at $298 \mathrm{~K}$ display intense structured bands in the $250-400 \mathrm{~nm}$ region (Fig. 2), which are similar in energy and shape to those found for the previously reported cyclometalated Pt(Iv) complexes ${ }^{12,13}$ and can be ascribed to essentially ${ }^{1} \mathrm{LC}$ transitions within the $\mathrm{C}^{\wedge} \mathrm{N}$ ligands with little MLCT character. The lowest-energy band shifts from 322 to $378 \mathrm{~nm}$ along the sequence $\mathbf{2 a} \rightarrow \mathbf{2 i}$, in line with the expected decreasing $\pi-\pi^{*}$ transition energies. This band has a significantly higher absorptivity for $2 \mathbf{e}$ and $2 \mathbf{f}$ (40 600 or $51500 \mathrm{M}^{-1} \mathrm{~cm}^{-1}$, respectively), compared to the rest of derivatives. Such intense absorptions are highly desirable for certain applications, such as bioimaging or photocatalysis.

The excitation and emission spectra of $2 \mathbf{a}-\mathbf{i}$ were registered in deaerated $\mathrm{CH}_{2} \mathrm{Cl}_{2}$ solutions at $298 \mathrm{~K}$ and butyronitrile (PrCN) glasses at $77 \mathrm{~K}$. The emission data are summarized in Table 1 and selected emission spectra at $298 \mathrm{~K}$ are shown in Fig. 2. The room-temperature emission spectra are vibrationally structured in all cases and the corresponding excitation spectra match the absorption profiles. Lifetimes are in the order of tens or 
Table 1 Emission data of complexes 2a-i

\begin{tabular}{|c|c|c|c|c|c|c|c|}
\hline \multirow[b]{2}{*}{ Complex } & \multicolumn{5}{|c|}{$298 \mathrm{~K}^{a}$} & \multicolumn{2}{|l|}{$77 \mathrm{~K}^{b}$} \\
\hline & $\begin{array}{l}\lambda_{\mathrm{em}}{ }^{c} / \\
\mathrm{nm}\end{array}$ & $\Phi^{d}$ & $\tau^{e} / \mu \mathrm{s}$ & $\begin{array}{l}k_{\mathrm{r}}^{f} \times \\
10^{-3} / \mathrm{s}^{-1}\end{array}$ & $\begin{array}{l}k_{\mathrm{nr}}^{g}{ }^{g} \times \\
10^{-3} / \mathrm{s}^{-1}\end{array}$ & $\lambda_{\mathrm{em}}{ }^{c} / \mathrm{nm}$ & $\tau^{e} / \mu \mathrm{s}$ \\
\hline $2 \mathbf{a}$ & 435 & 0.57 & 154 & 3.70 & 2.79 & 430 & 267 \\
\hline $2 b$ & 447 & 0.60 & 99.7 & 6.02 & 4.01 & 442 & 215 \\
\hline $2 \mathrm{c}$ & 453 & 0.51 & 98.0 & 5.20 & 5.00 & 447 & 258 \\
\hline $2 d$ & 458 & 0.28 & 74.3 & 3.77 & 9.69 & 451 & 478 \\
\hline $2 e$ & 484 & 0.81 & 193 & 4.20 & 0.98 & 481 & 254 \\
\hline $2 f$ & 512 & 0.20 & 110 & 1.82 & 7.27 & 504 & 450 \\
\hline $2 g$ & 514 & 0.22 & 81.8 & 2.69 & 9.53 & 508 & 289 \\
\hline $2 h$ & 565 & 0.05 & 17.2 & 2.91 & 55.23 & 553 & 65.6 \\
\hline $2 \mathrm{i}$ & 585 & 0.04 & 14.9 & 2.68 & 64.43 & 558 & 121 \\
\hline
\end{tabular}

${ }^{a}$ In deaerated $\mathrm{CH}_{2} \mathrm{Cl}_{2}$ solution $\left(\right.$ ca. $\left.5 \times 10^{-6} \mathrm{M}\right) .{ }^{b}$ In deaerated PrCN ${ }^{c}$ Highest-energy emission peak. ${ }^{d}$ Absolute quantum yield. ${ }^{e}$ Emission lifetime. ${ }^{f}$ Radiative rate constant, $k_{\mathrm{r}}=\Phi / \tau .{ }^{g}$ Nonradiative rate constant, $k_{\mathrm{nr}}=(1-\Phi) / \tau$.

hundreds of microseconds and Stokes shifts are in the range 6000-9000 $\mathrm{cm}^{-1}$. The emission energies decrease on going from $2 \mathbf{a}$ to $2 \mathbf{i}$, in accord with the $\pi-\pi^{*}$ transition energies of the $\mathrm{C}^{\wedge} \mathrm{N}$ ligands, and the associated emission colours range from blue to orange. The vibrational structure becomes better resolved in frozen glasses at $77 \mathrm{~K}$ and lifetimes increase as a consequence of the partial suppression of non-radiative processes. The mentioned characteristics are indicative of an essentially ${ }^{3} \mathrm{LC}$ emitting state, as found for the previously reported triscyclometalated Pt(Iv) complexes. ${ }^{12,13}$ In fact, the emission spectra of $\mathbf{2 b}$ and $f a c-\left[\mathrm{Pt}(\mathrm{ppy})_{3}\right]^{+}$are practically identical (Fig. S6, ESI $\dagger$ ).

The new compounds are very bright emitters in $\mathrm{CH}_{2} \mathrm{Cl}_{2}$ solutions at room temperature, showing quantum yields $(\Phi)$ higher than 0.20 , with the exception of $2 \mathbf{h}$ and $2 \mathbf{i}$. An inspection of radiative and non-radiative rate constants ( $k_{\mathrm{r}}$ and $k_{\mathrm{nr}}$, respectively) shows that, while $k_{\mathrm{r}}$ values remain within the same order of magnitude along the series, $k_{\mathrm{nr}}$ values are significantly higher for $\mathbf{2 h}$ and $\mathbf{2 i}$, indicating that non-radiative processes are more effective in these cases; reasonably, this behaviour can be ascribed to the lower energy of the emitting state in these derivatives, which leads to a more significant deactivation through vibrational coupling to the ground state. ${ }^{18}$ Both $k_{\mathrm{r}}$ and $k_{\mathrm{nr}}$ are higher in complexes $\mathbf{2}$ than in the respective tris-cyclometalated complexes $f a c-\left[\mathrm{Pt}\left(\mathrm{C}^{\wedge} \mathrm{N}\right)_{3}\right]^{+}$or $m e r-\left[\mathrm{Pt}(\mathrm{ppy})_{2}\left(\mathrm{C}^{\prime \wedge} \mathrm{N}^{\prime}\right)\right]^{+}$bearing the same $\mathrm{C}^{\wedge} \mathrm{N}$ or $\mathrm{C}^{\prime \wedge} \mathrm{N}^{\prime}$ ligand in all the studied cases $\left(\mathrm{C}^{\wedge} \mathrm{N}=\right.$ dfppy, ppy, tpy; $\mathrm{C}^{\prime \wedge} \mathrm{N}^{\prime}=$ thpy, piq). ${ }^{12,13}$ Notwithstanding, the new compounds exhibit higher quantum yields because the relative increase is much higher in $k_{\mathrm{r}}$ than in $k_{\mathrm{nr}}$. This fact suggests a significantly higher MLCT contribution to the emitting ${ }^{3} \mathrm{LC}$ state, which is known to accelerate the radiative transition to the ground state. ${ }^{9 c, 19}$ In turn, the higher MLCT character is attributable to the strong electron-donating ability of the methyl ligand and the uncharged nature of complexes 2, which must necessarily correlate with a higher energy of the occupied metal d orbitals relative to the cationic tris-cyclometalated complexes and an increased contribution of these orbitals to the HOMO. The Bppy complex 2e shows an impressive quantum yield of 0.81 , comparable to the best $\mathrm{Pt}(\mathrm{II})$ and $\mathrm{Ir}(\mathrm{III})$ emitters ${ }^{8 f, 19,20}$ and represents the most efficient $\mathrm{Pt}$ (Iv) complex ever reported. The excellent
Table 2 Electrochemical data ${ }^{a}$ and HOMO/LUMO energy estimations ${ }^{b}$ for complex $\mathbf{2 b}$ compared with fac-[Pt(ppy) $\left.)_{3}\right] \mathrm{OTf}$

\begin{tabular}{lccccc}
\hline Complex & $E_{\mathrm{pa}}{ }^{c}$ & $E_{\mathrm{pc}}{ }^{d}$ & $E_{\text {HOMO }}$ & $E_{\mathrm{LUMO}}$ & $\Delta E_{\text {HOMO-LUMO }}$ \\
\hline $\mathbf{2 b}$ & 1.93 & -1.83 & -6.50 & -2.97 & 3.53 \\
fac $\left[\mathrm{Pt}(\mathrm{ppy})_{3}\right]^{+}$ & $-e^{e}$ & -1.80 & - & -2.71 & -
\end{tabular}

${ }^{a}$ In $\mathrm{V}$ relative to SCE, measured in $0.1 \mathrm{M}\left(\mathrm{Bu}_{4} \mathrm{~N}\right) \mathrm{PF}_{6}$ anhydrous MeCN solution at $100 \mathrm{mV} \mathrm{s}^{-1} \cdot{ }^{b} \mathrm{In} \mathrm{eV}{ }^{c}$ Irreversible anodic peak potential. ${ }^{d}$ First irreversible cathodic peak potential. ${ }^{e}$ Outside solvent window.

phosphorescent efficiency of metal complexes with the Bppy ligand has been previously ascribed to the enhancement of MLCT character in the excited state, which increases $k_{\mathrm{r}}{ }^{21}$ in addition, this effect combines with an important decrease in $k_{\mathrm{nr}}$ owing to the presence of the bulky $\mathrm{BMes}_{2}$ substituent.

The emission spectra of $\mathbf{2} \mathbf{b}$ were also registered at concentrations in the range $10^{-5}$ to $10^{-3} \mathrm{M}$ in $\mathrm{CH}_{2} \mathrm{Cl}_{2}$ at $298 \mathrm{~K}$ to probe possible concentration effects (Fig. S8, ESI $\dagger$ ). Although the emission profile did not change, a dramatic decrease in intensity was observed at high concentrations, indicating intermolecular quenching. A similar effect has been observed for tris-cyclometalated $\mathrm{Pt}(\mathrm{Iv})$ derivatives ${ }^{12}$ and other octahedral emitters, ${ }^{22}$ most probably due to triplet-triplet annihilation. $^{23}$

Additional insight into the electronic properties of the new complexes was gathered by comparing the electrochemical data of $\mathbf{2 b}$, obtained using cyclic voltammetry in MeCN solution, with those of $f a c-\left[\mathrm{Pt}(\mathrm{ppy})_{3}\right]^{+13}$ (Table 2). The cyclic voltammogram of $2 \mathbf{b}$ (Fig. S9, ESI $\dagger$ ) shows several irreversible reduction peaks that resemble those observed for $f a c-\left[\mathrm{Pt}(\mathrm{ppy})_{3}\right]^{+}$; the first of them corresponds a one-electron process and occurs at almost the same potential, indicating that the LUMO is based on the ppy ligand. However, while the oxidation of the tris-cyclometalated complex falls outside the solvent discharge limit, the oxidation of $\mathbf{2 b}$ occurs at a less positive potential and can be observed, which implies a significantly higher HOMO energy and is consistent with the above-discussed higher metal orbital involvement.

Photostability is an important issue in compounds designed for optical or photochemical applications. We have previously observed that tris-cyclometalated Pt(Iv) complexes containing one thpy or piq ligand were not stable upon exposure to UV light. ${ }^{13}$ In contrast, derivatives $2 \mathbf{g}$ and $2 \mathbf{h}$, which bear these ligands, remained unaltered upon irradiation with a $36 \mathrm{~W} \mathrm{UVB}$ lamp in $\mathrm{CD}_{2} \mathrm{Cl}_{2}$ solution for 4 hours (Fig. S10 and S11, ESI $\dagger$ ).

In summary, we report the one-pot method for the synthesis of luminescent bis-cyclometalated chloro(methyl)platinum(Iv) complexes featuring long excited-state lifetimes and remarkably high quantum yields that can reach the level of the best $\mathrm{Pt}(\mathrm{II})$ and $\operatorname{Ir}(\mathrm{III})$ emitters. Their easier synthesis, wider tunability and higher efficiencies with respect to the previously reported $\mathrm{Pt}(\mathrm{Iv})$ emitters make them an attractive alternative for diverse applications, including photocatalysis, bioimaging or chemosensing.

This work was supported by Ministerio de Economía y Competitividad, Spain (project CTQ2011-24016, with FEDER support, and FPU grant to F. J.) and Universidad de Murcia. 


\section{Notes and references}

1 V. W.-W. Yam and K. M.-C. Wong, Chem. Commun., 2011, 47, 11579. 2 (a) M. S. Lowry and S. Bernhard, Chem. - Eur. J., 2006, 12, 7970; (b) J. Kalinowski, V. Fattori, M. Cocchi and J. A. G. Williams, Coord. Chem. Rev., 2011, 255, 2401; (c) W.-Y. Wong and C.-L. Ho, J. Mater. Chem., 2009, 19, 4457; (d) R. D. Costa, E. Ortí, H. J. Bolink, F. Monti, G. Accorsi and N. Armaroli, Angew. Chem., Int. Ed., 2012, 51, 8178.

3 (a) B. Higgins, B. A. DeGraff and J. N. Demas, Inorg. Chem., 2005, 44, 6662; (b) D.-L. Ma, V. P.-Y. Ma, D. S.-H. Chan, K.-H. Leung, H.-Z. He and C.-H. Leung, Coord. Chem. Rev., 2012, 256, 3087.

4 (a) C. K. Prier, D. A. Rankic and D. W. C. MacMillan, Chem. Rev., 2013, 113, 5322; (b) J. M. R. Narayanam and C. R. J. Stephenson, Chem. Soc. Rev., 2011, 40, 102; (c) D. M. Schultz and T. P. Yoon, Science, 2014, 343, 985.

5 (a) Q. Zhao, C. Huang and F. Li, Chem. Soc. Rev., 2011, 40, 2508; (b) E. Baggaley, J. A. Weinstein and J. A. G. Williams, Coord. Chem. Rev., 2012, 256, 1762; (c) E. Baggaley, S. W. Botchway, J. W. Haycock, H. Morris, I. V. Sazanovich, J. A. G. Williams and J. A. Weinstein, Chem. Sci., 2014, 5, 879.

6 (a) M. Grätzel, Acc. Chem. Res., 2009, 42, 1788; (b) C. A. Bignozzi, R. Argazzi, R. Boaretto, E. Busatto, S. Carli, F. Ronconi and S. Caramori, Coord. Chem. Rev., 2013, 257, 1472.

7 (a) A. Ruggi, F. W. B. van Leeuwen and A. H. Velders, Coord. Chem. Rev., 2011, 255, 2542; (b) P. I. Djurovich, D. Murphy, M. E. Thompson, B. Hernandez, R. Gao, P. L. Hunt and M. Selke, Dalton Trans., 2007, 3763; (c) R. Lincoln, L. Kohler, S. Monro, H. Yin, M. Stephenson, R. Zong, A. Chouai, C. Dorsey, R. Hennigar, R. P. Thummel and S. A. McFarland, J. Am. Chem. Soc., 2013, 135, 17161.

8 (a) J. Brooks, Y. Babayan, S. Lamansky, P. I. Djurovich, I. Tsyba, R. Bau and M. E. Thompson, Inorg. Chem., 2002, 41, 3055; (b) A. F. Rausch, L. Murphy, J. A. G. Williams and H. Yersin, Inorg. Chem., 2012, 51, 312; (c) S. Culham, P.-H. Lanoë, V. L. Whittle, M. C. Durrant, J. A. G. Williams and V. N. Kozhevnikov, Inorg. Chem., 2013, 52, 10992; (d) W. A. Tarran, G. R. Freeman, L. Murphy, A. M. Benham, R. Kataky and J. A. G. Williams, Inorg. Chem., 2014, 53, 5738; (e) A. M. Prokhorov, T. Hofbeck, R. Czerwieniec, A. F. Suleymanova, D. N. Kozhevnikov and H. Yersin, J. Am. Chem. Soc., 2014, 136, 9637; $(f)$ S. Huo, J. Carroll and D. A. K. Vezzu, Asian J. Org. Chem., 2015, 4, 1210.

9 (a) S. Lamansky, P. Djurovich, D. Murphy, F. Abdel-Razzaq, R. Kwong, I. Tsyba, M. Bortz, B. Mui, R. Bau and M. E. Thompson, Inorg. Chem., 2001, 40, 1704; (b) A. B. Tamayo, B. D. Alleyne, P. I. Djurovich, S. Lamansky, I. Tsyba, N. N. Ho, R. Bau and M. E. Thompson, J. Am. Chem. Soc., 2003, 125, 7377; (c) P.-T. Chou, Y. Chi, M.-W. Chung and C.-C. Lin, Coord. Chem. Rev., 2011, 255, 2653; (d) Y. You and S. Y. Park,
Dalton Trans., 2009, 1267; (e) Y. You and W. Nam, Chem. Soc. Rev., 2012, 41, 7061; $(f)$ K. Beydoun, M. Zaarour, J. A. G. Williams, T. Roisnel, V. Dorcet, A. Planchat, A. Boucekkine, D. Jacquemin, H. Doucet and V. Guerchais, Inorg. Chem., 2013, 52, 12416; $(g)$ Y. You, S. Cho and W. Nam, Inorg. Chem., 2014, 53, 1804; (h) P.-H. Lanoe, C. M. Tong, R. W. Harrington, M. R. Probert, W. Clegg, J. A. G. Williams and V. N. Kozhevnikov, Chem. Commun., 2014, 50, 6831; (i) B. J. Coe, M. Helliwell, S. Sánchez, M. K. Peers and N. S. Scrutton, Dalton Trans., 2015, 44, 15420.

10 L. Chassot, A. Von Zelewsky, D. Sandrini, M. Maestri and V. Balzani, J. Am. Chem. Soc., 1986, 108, 6084.

11 (a) H. Kunkely and A. Vogler, Coord. Chem. Rev., 1991, 111, 15; (b) K. P. Balashev, J. Simon and P. C. Ford, Inorg. Chem., 1991, 30, 859; (c) D. M. Jenkins and S. Bernhard, Inorg. Chem., 2010, 49, 11297.

12 F. Juliá, D. Bautista, J. M. Fernández-Hernández and P. GonzálezHerrero, Chem. Sci., 2014, 5, 1875.

13 F. Juliá, G. Aullón, D. Bautista and P. González-Herrero, Chem. - Eur. J., 2014, 20, 17346.

14 G. S. Hill, M. J. Irwin, C. J. Levy, L. M. Rendina, R. J. Puddephatt, R. A. Andersen and L. McLean, in Inorganic Syntheses, ed. M. Y. Darensbourg, John Wiley \& Sons, Inc., 1998, p. 149.

15 (a) M. G. Haghighi, M. Rashidi, S. M. Nabavizadeh, S. Jamali and R. J. Puddephatt, Dalton Trans., 2010, 39, 11396; (b) S. Jamali, R. Czerwieniec, R. Kia, Z. Jamshidi and M. Zabel, Dalton Trans., 2011, 40, 9123; (c) S. Jamali, S. M. Nabavizadeh and M. Rashidi, Inorg. Chem., 2008, 47, 5441.

16 (a) J. Mamtora, S. H. Crosby, C. P. Newman, G. J. Clarkson and J. P. Rourke, Organometallics, 2008, 27, 5559; (b) C. P. Newman, K. Casey-Green, G. J. Clarkson, G. W. V. Cave, W. Errington and J. P. Rourke, Dalton Trans., 2007, 3170.

17 CCDC 1435571-1435574.

18 (a) K. F. Freed and J. Jortner, J. Chem. Phys., 1970, 52, 6272; (b) J. Englman and J. Jortner, Mol. Phys., 1970, 18, 145.

19 H. Yersin, A. F. Rausch, R. Czerwieniec, T. Hofbeck and T. Fischer, Coord. Chem. Rev., 2011, 255, 2622.

20 Y. Chi and P.-T. Chou, Chem. Soc. Rev., 2010, 39, 638.

21 (a) Z. M. Hudson, C. Sun, M. G. Helander, H. Amarne, Z.-H. Lu and S. Wang, Adv. Funct. Mater., 2010, 20, 3426; (b) Z. M. Hudson, C. Sun, M. G. Helander, Y.-L. Chang, Z.-H. Lu and S. Wang, J. Am. Chem. Soc., 2012, 134, 13930; (c) Y.-L. Rao and S. Wang, Inorg. Chem., 2009, 48, 7698; (d) Z. M. Hudson and S. Wang, Dalton Trans., 2011, 40, 7805.

22 C.-H. Yang, M. Mauro, F. Polo, S. Watanabe, I. Muenster, R. Fröhlich and L. De Cola, Chem. Mater., 2012, 24, 3684.

23 M. Baldo, C. Adachi and S. Forrest, Phys. Rev. B: Condens. Matter Mater. Phys., 2000, 62, 10967. 